\title{
PERSEPSI PETANI TERHADAP VIDEO PENYULUHAN SISTEM OF RICE INTENSIFICATION (SRI) SEBAGAI MEDIA INFORMASI PERTANIAN ORGANIK BAGI PETANI \\ (Studi Kasus di Kelompok Tani Bina Lingkungan Kecamatan Andong Kabupaten Boyolali)
}

\author{
Emi Widiyanti ${ }^{1)}$, Arief Iman Santoso ${ }^{2)}$ \\ ${ }^{1)}$ Program Studi Penyuluhan dan Komunikasi Pertanian Fakultas Pertanian UNS \\ email: emin4y@gmail.com \\ ${ }^{2)}$ Program Studi Desain Komunikasi Visual Fakultas Seni Rupa dan Desain UNS \\ email: aripdisini@gmail.com
}

\begin{abstract}
The study aims to determine the farmer's perception of agricultural extension video System of Rice Intensification (SRI) as a information medium of organic agricultural for farmers. This research was a descriptive case study approach. Implementation of the research was conducted using survey techniques to 30 farmers in the Andong village, Boyolali District. The results showed that $73.33 \%$ of respondents had a good perception of SRI video capabilities in attracting the attention of farmers, $70.00 \%$ of respondents had a good perception of the ability of SRI video shows the importance of organic farming, $73.33 \%$ of respondents had a good perception the ability of the video to shows the solution for farmers problem and $83.33 \%$ of respondents had a good perception of the SRI video capabilities in showing a clear process, the audio and visual was attractive and easy to understand. It was concluded that the farmers have a good perception of the agricultural extension SRI video is quite effective as a education medium of organic agricultural for the farmers that are containt of attention, needs, satisfaction and visualization. Expected media outreach video was capable of facilitating the dissemination of SRI among farmers.
\end{abstract}

Keywords: agriculture extention video, perception, System of Rice Intensification (SRI)

\section{PENDAHULUAN}

Terobosan kebijakan pertanian dalam usahatani padi oleh pemerintah terkait dengan upaya swasembada pangan khususnya beras sangat diperlukan. Pemerintah dalam upaya swasembada pangan untuk memenuhi kebutuhan pangan yang terus meningkat, telah mengambil kebijakan pertanian dengan tujuan pencapaian swasembada pangan berkelanjutan. Untuk pencapaian swasembada berkelanjutan tersebut diperlukan upaya peningkatan produksi, salah satunya yaitu pengembangan System of Rice Intensification (SRI). Metode SRI adalah metode penetapan produksi padi beririgasi, yang dilakukan perubahan manajemen tanaman, tanah, air dan nutrisi. Keuntungan yang diperoleh dari metode SRI ini yaitu terpelihara kondisi tanah, pertumbuhan akar tanaman lebih lebar, dan produktifitas tinggi (Ukrita et al. 2011).

System of Rice Intensification (SRI) menurut Direktorat Jenderal Prasarana dan Sarana Pertanian (2014) adalah cara budidaya padi pada lahan sawah beririgasi dan lahan tadah hujan yang ketersediaan airnya terjamin secara intensif dan efisien dalam pengolahan tanah, tanaman dan pengelolaan air melalui pemberdayaan petani/ kelompok tani/ P3A/ Gapoktan. Penanaman padi pola SRI adalah cara budidaya tanam padi yang ramah lingkungan, dimulai dari proses olah tanah dengan memberikan asupan bahan organik (kompos), melakukan uji benih bermutu/bernas, benih melalui persemaian kering, pengelolaan air yang intermitten (pemberian air secara macak-macak), tanam tunggal, bibit muda, dangkal dan akar horizontal serta jarak tanam yang dijarangkan yaitu $25 \times 25 \mathrm{~cm}$ atau $30 \times 30 \mathrm{~cm}$

Menurut Purwasasmita dan Alik Sutaryat (2014), beberapa alasan menggunakan metode SRI adalah : (a) merupakan usahatani ramah lingkungan dan berkelanjutan, (b) menghemat penggunaan air irigasi sampai dengan $40 \%$, (c) produksi tinggi hingga di atas rata-rata nasional (sekitar 7,44 ton $\mathrm{gkg} / \mathrm{ha}$ ) dan (d) harga jual beras organik lebih tinggi. Lebih lanjut dijelaskan perbedaan utama metode sri dengan metode konvensional antara lain : bibit harus ditanam muda, ditanam satu-satu, 
ditanam dengan jarak lebar, ditanam dangkal, tidak digenangi air, penggunaan pupuk dan pestisida organik dan menekankan penggunaan mikroorganisme lokal (mol) yang dikembangkan setempat.

Agar metode ini diterapkan oleh masyarakata petani diperlukan upaya diseminasi melalui kegiatan penyuluhan secara serempak di seluruh wilayah. Dalam proses kegiatan penyuluhan diperlukan unsur-unsur pendukung kegiatan penyuluhan diantaranya adalah peran penyuluh, metoda dan perlengakapan penyuluhan itu sendiri yang meliputi alat bantu dan media penyuluhan yang mampu mendorong keinginan petani untuk mengadopsi metoda SRI.

Upaya pemerintah untuk mendorong percepatan penerapan metoda SRI itu sendiri, menghadapi permasalahan diantaranya permasalahan yang ada pada kegiatan penyuluhan pertanian yang merupakan ujung tombak pembangunan pertanian karena kegiatan penyuluhan merupakan proses edukasi bagi petani agar mau menerapkan metoda SRI. Marsh dan Pannel (1999) mengungkapkan adanya dua kendala terkait diantara empat masalah yang akan dihadapi penyuluhan pertanian di awal abad 21 ini adalah kemampuan penelitian dan aliran informasi yang dihasilkan serta kendala dalam metoda penyuluhan dan alih teknologi.

Kondisi saat ini menujukkan bahwa bangsa Indonesia mengalami kekurangan tenaga penyuluh pertanian. Agroindonesia (2015) menujukkan bahwa jika dibandingkan dengan jumlah petani dan luas lahan pertanian di dalam negeri, jumlah penyuluh yang ada sekarang ini tidaklah ideal. Dimana data Kementerian Pertanian menyebutkan jumlah tenaga penyuluh pertanian di Indonesia saat ini sebanyak 47.412 orang dan untuk idealnya, jumlah tenaga penyuluh pertanian di Indonesia adalah sebanyak 98.356 orang dengan dasar para kebutuhan satu penyuluh untuk setiap satu desa, ditambah kebutuhan penyuluh yang ditempatkan di kantor-kantor penyuluh di tingkat wilayah.

Melihat adanya keterbatasan jumlah tenaga penyuluh, maka keberadaan media penyuluhan yang efektif menjangkau sasaran dalam jumlah yang banyak sangat dibutuhkan untuk menunjang proses edukasi petani maupun mengatasi keterbatasan jumlah penyuluh ini. Menurut Anonim (2016) berbagai media penyuluhan dapat digunakan untuk megemas informasi dan teknologi yang akan disampaikan kepada petani sebagai pengguna teknologi seperti : media cetak, media audio, media audio visual, media berupa obyek fisik atau benda nyata. Secara umum dapat dikatakan bahwa media merupakan suatu perantara yang digunakan dalam proses belajar. Tujuan penggunaan media adalah untuk memperjelas informasi yang disampaikan sehingga dapat merangsang fikiran, perasaan, perhatian dan kemampuan sasaran. Mardikanto (1993) mengartikan alat peraga sebagai alat atau benda yang dapat diamati, didengar, diraba, atau dirasakan oleh indera manusia, yang berfungsi sebagai alat untuk meragakan dan atau menjelaskan uraian yang disampaikan secara lisan (oleh penyuluh) guna membantu proses belajar penerima manfaat penyuluhan agar materi penyuluhan lebih mudah diterima dan dipahami oleh penerima manfaat penyuluhan yang bersangkutan.

Melihat kondisi dan permasalahan dalam penyuluhan pertanian, Fakultas Pertanian khususnya Program Studi Penyuluhan dan Komunikasi Pertanian telah memproduksi sebuah media informasi metode System of Rice Intensification (SRI) yang berupa video penyuluhan. Video penyuluhan System of Rice Intensification (SRI) telah diluncurkan ke masyarakat petani khususnya kelompok tani Bina Lingkungan di Kecamatan Andong Kabupaten Boyolali pada awal bulan Oktober 2015. Media audio visual (video) ini berisikan materi metoda SRI mulai dari pengolahan tanah, pembenihan, penanaman, pemupukan, penyiangan, inpeksi (pengendalian hama penyakit) dan pemanenan.

Untuk melihat sejauh mana respon masyarakat tani khususnya kelompok tani Bina Lingkungan terhadap video penyuluhan SRI, dilakukan sebuah penelitian yang bertujuan mengkaji persepsi petani terhadap video penyuluhan pertanian System of Rice Intensification (SRI) sebagai media informasi pertanian organik bagi petani. Persepsi menurut Desiderato dalam Rakhmat (1999), adalah pengalaman tentang objek, peristiwa atau hubungan-hubungan yang diperoleh dengan menyimpulkan informasi dan menafsirkan pesan. Sedangkan Robbins dan Judge (2007), mendefinisikan persepsi sebagai proses di mana individu mengatur dan menginterpretasikan kesan-kesan sensoris mereka guna memberikan arti bagi lingkungan 
mereka. Interpretasi menurut kamus Besar Bahasa Indonesia (2001) adalah pemberian kesan, pendapat atau pandangan teoritis terhadap sesuatu, sehingga dapat dikatakan persepsi adalah kesan atau pendapat terhadap suatu objek. Adapun persepsi petani terhadap video SRI sebagai media edukasi dilakukan dengan pendekatan terhadap sistematika pesan yang disampaikan oleh video SRI. Monroe dalam Syam dan Sugiana (2007) memformulasikan sistematika penyusunan pesan berdasarkan ANSVA (Attention, Needs, Satisfaction, Visualization dan Action).

\section{METODE PENELITIAN}

Penelitian ini merupakan penelitian deskriptif dengan pendekatan studi kasus pada sebuah kelompok tani yang telah menggunakan video penyuluhan System of Rice Intensification (SRI) yaitu kelompok tani Bina Lingkungan di Desa Andong Kecamatan Andong Kabupaten Boyolali. Pelaksanaan penelitian yang dilakukan dengan menggunakan metode survey. Penelitian survei merupakan penelitian yang bertujuan untuk mengumpulkan data dengan menelaah sampel dari suatu populasi yang tersedia (Juliandi et al. 2014). Menurut Kriyantono (2006), survey merupakan metode riset dengan menggunakan kuisioner sebagai instrument pengumpulan datanya.

Indikator yang digunakan untuk mengukur kelayakan video penyuluhan SRI sebagai media informasi pertanian organik meliputi : (1) Attention yaitu kemampuan video menunjukkan metoda SRI sebagai sebuah issue yang menarik bagi petani); (2) Needs yaitu kemampuan video menunjukkan permasalahanyang dihadapi dalam upaya pemenuhan kebutuhan pangan dan pentingnya pertanian organik; (3) Satisfaction yaitu kemampuan video menunjukkan metode SRI merupakan solusi terhadap masalah petani; (4) Visualization yaitu kemampuan video memberikan visualisasi terhadap metoda SRI secara jelas dan menarik. Visualisasi diukur dari kemampuan menunjukkan proses yang jelas, audio dan visual yang menarik dan mudah dipahami.

Populasi dalam penelitian adalah anggota kelompok tani Bina Lingkungan. Sampel diambil secara random sampling sebanyak 30 petani anggota. Data yang digunakan dalam penelitian ini adalah data primer yang diperoleh melalui wawancara langsung dengan kuisioner dan data sekunder yang diperoleh melalui observasi langsung terhadap media video SRI. Data yang diperoleh dianalisis secara deskripstif analitis menggunakan tabel distribusi frekuensi.

\section{HASIL DAN PEMBAHASAN}

Media audio visual (video) dipilih sebagai media edukasi metode SRI untuk petani karena media ini memiliki beberapa kelebihan diantaranya adalah kemampuan menjangkau audiens yang banyak karena dapat dilihat secara individu maupun bersama-sama (kolektif) selain itu media ini dapat diputar atau dilihat secara berulang-ulang sesuai kebutuhan audiens atau petani. Sehingga media ini dapat dijadikan salahsatu media yang dapat membantu keterbatasan jumlah penyuluh pertanian saat ini. Dalam penelitian ini video SRI telah diluncurkan ke kelompok Tani Bina Lingkungan sejak Bulan Oktober 2015 dan telah digunakan sebagai media penyuluhan sebanyak tiga kali oleh kelompok tersebut. Sebuah media dalam hal ini adalah video dapat dikatakan layak sebagai sebuah media komunikasi/informasi jika video tersebut mengandung beberapa unsur yaitu attention, needs, satisfaction dan unsur visualization. Berikut hasil kajian persepsi petani terhadap efektifitas video metoda SRI sebagai media edukasi bagi petani, dengan melihat persepsi mereka terhadap unsur attention, needs, satisfaction dan unsur visualization dalam video SRI tersebut.

\section{Persepsi petani terhadap unsur attention video penyuluhah SRI}

Persepsi atau kesan petani terhadap unsur attention video penyuluhan SRI adalah kesan petani terhadap kemampuan media menunjukkan metoda SRI sebagai sebuah issue yang menarik bagi petani. Hal ini diukur dengan kemampuan video memberikan gambaran umum tentang metoda SRI mulai dari penyampaian alasan penggunaan metoda SRI, keunggulan metoda SRI, proses budidaya padi organik dalam metoda SRI dan gambaran proses pasca panen dan pemasaran padi organik. Berikut distribusi frekuensi petani berdasarkan persepsinya terhadap unsur attention video penyuluhan SRI.

Tabel 1 menunjukkan bahwa sebagai besar $(73,33 \%)$ memiliki kesan yang baik terhadap kemampuan video SRI dalam 
menyajikan metoda SRI secara umum. Artinya sebagai sebuah media edukasi, video penyuluhan SRI telah mampu memberikan gambaran SRI mulai alasan penggunaan metoda SRI, keunggulan metoda SRI, proses budidaya padi organik dalam metoda SRI dan gambaran proses pasca panen dan pemasaran padi organik secara komprehensif.

Tabel 1. Persepsi petani terhadap unsur attention video penyuluhan SRI

\begin{tabular}{lccc}
\hline Persepsi & Skor & $\begin{array}{c}\text { Jumlah } \\
\text { responden } \\
\text { (orang) }\end{array}$ & $\begin{array}{c}\text { Persentase } \\
(\%)\end{array}$ \\
\hline Baik & $9,4-12,0$ & 22 & 73.33 \\
Cukup baik & $6,7-9,3$ & 8 & 26.67 \\
Tidak Baik & $4,0-6,6$ & 0 & 0.00 \\
\hline & Jumlah & 30 & 100,00 \\
\hline
\end{tabular}

Sumber : Analisa data primer, 2015.

\section{Persepsi petani terhadap unsur needs video penyuluhah SRI}

Persepsi atau kesan petani terhadap unsur needs video penyuluhan SRI adalah kesan petani terhadap kemampuan video menunjukkan permasalahan yang dihadapi dalam upaya pemenuhan kebutuhan pangan dan pentingnya pertanian organik. Hal ini diukur dengan kemampuan video memberikan gambaran tentang permasalahan yang dihadapi petani berkaitan dengan usahatani taninya antara lain permasalahan pencemaran lingkungan dan degradasi kesuburan lahan, permasalahan kekurangan air, kelangkaan pupuk bersubsidi dan mahalnya harga pupuk. Metoda SRI merupakan salah satu upaya untuk menjawab permasalahan tersebut. Berikut distribusi frekuensi petani berdasarkan persepsinya terhadap unsur needs video penyuluhan SRI.

Tabel 2. Persepsi petani terhadap unsur needs video penyuluhan $S R I$

\begin{tabular}{lccc}
\hline Persepsi & Skor & $\begin{array}{c}\text { Jumlah } \\
\text { responden } \\
\text { (orang) }\end{array}$ & $\begin{array}{c}\text { Persentase } \\
(\%)\end{array}$ \\
\hline Baik & $9,4-12,0$ & 21 & 70.00 \\
Cukup baik & $6,7-9,3$ & 8 & 26.67 \\
Tidak Baik & $4,0-6,6$ & 1 & 3.33 \\
\hline & Jumlah & 30 & 100,00 \\
\hline
\end{tabular}

Sumber : Analisa data primer, 2015.

Tabel 2 menunjukkan bahwa sebagai besar $(70,00 \%)$ memiliki kesan yang baik terhadap kemampuan video SRI dalam menunjukkan permasalahan-permasalahan petani yang harus segera diatasi. Dengan menunjukkan permsalahan petani, sebagai media edukasi video penyuluhan SRI mampu membangkitkan kebutuhan (needs) petani untuk mempelajari dan menerapkan atau mengadopsi metoda SRI dalam usahatani mereka.

\section{Persepsi petani terhadap unsur satisfaction video penyuluhah SRI}

Persepsi atau kesan petani terhadap unsur satisfaction video penyuluhan SRI adalah kesan petani terhadap kemampuan video menunjukkan metode SRI merupakan solusi terhadap masalah petani. Hal ini diukur dengan kemampuan video memberikan penjelasan tentang manfaat metoda SRI untuk solusi terhadap permasalahan yang dihadapi petani. Berikut distribusi frekuensi petani berdasarkan persepsinya terhadap unsur satisfaction dalam video penyuluhan SRI.

Tabel 3. Persepsi petani terhadap unsur satisfaction video penyuluhan SRI

\begin{tabular}{lccc}
\hline Persepsi & Skor & $\begin{array}{c}\text { Jumlah } \\
\text { responden } \\
\text { (orang) }\end{array}$ & $\begin{array}{c}\text { Persentase } \\
(\%)\end{array}$ \\
\hline Baik & $4,8-6,0$ & 22 & 73.33 \\
Cukup baik & $3,4-4,7$ & 8 & 26.67 \\
Tidak Baik & $2,0-3,3$ & 0 & 0.00 \\
\hline \multicolumn{2}{l}{ Jumlah } & 30 & 100,00 \\
\hline
\end{tabular}

Sumber : Analisa data primer, 2015.

Tabel 3 menunjukkan bahwa sebagai besar $(73,33 \%)$ memiliki kesan yang baik terhadap kemampuan video SRI dalam menunjukkan solusi-solusi bagi permasalahan mereka. Solusi yang digambarkan dan disajikan dalam video penyuluhan SRI ini adalah: 1) penggunakan pupuk dan pestisida organik dan menekankan penggunaan mikroorganisme lokal (mol) yang dikembangkan setempat merupakan bentuk usahatani ramah lingkungan dan berkelanjutan; 2) tidak digenangi air merupakan solusi untuk menghemat penggunaan air irigasi sampai dengan $40 \%$; 3 ) penggunaan bibit muda, penanaman satu persatu dengan jarak yang lebar akan menghasilkan produksi padi yang tinggi dan 4) dengan harga jual beras organik lebih tinggi akan meningkatkan pendapatan petani.

Menunjukkan manfaat dari buah inovasi, dalam hal ini adalah metoda SRI merupakan salah satu syarat dalam proses belajar. Seperti yang dikemukakan oleh Mardikanto (2007) bahwa dalam proses belajar harus mengandung prinsip akibat (effect) dengan menunjukkan manfaat yang diperoleh setelah 
mempelajari sesuatu hal. Sebagai media edukasi, video penyuluhan SRI telah menerapkan prinsip akibat (effect).

\section{Persepsi petani terhadap unsur visualization video penyuluhah SRI}

Persepsi atau kesan petani terhadap unsur visualization video penyuluhan SRI adalah kesan petani terhadap kemampuan video memberikan visualisasi terhadap metoda SRI secara jelas dan menarik. Visualisasi diukur dari kemampuan menunjukkan proses yang jelas, audio dan visual yang menarik dan mudah dipahami. Berikut distribusi frekuensi petani berdasarkan persepsinya terhadap unsur visualization dalam video penyuluhan SRI.

Tabel 4. Persepsi petani terhadap unsur visualization video penyuluhan System SRI

\begin{tabular}{lccc}
\hline Persepsi & Skor & $\begin{array}{c}\text { Jumlah } \\
\text { responden } \\
\text { (orang) }\end{array}$ & $\begin{array}{c}\text { Prosentase } \\
(\boldsymbol{\%})\end{array}$ \\
\hline Baik & $16,4-21,0$ & 25 & 83.33 \\
Cukup baik & $11,7-16,3$ & 5 & 16.67 \\
Tidak Baik & $7,0-11,6$ & 0 & 0.00 \\
\hline & Jumlah & 30 & 100,00 \\
\hline
\end{tabular}

Sumber : Analisa data primer, 2015.

Tabel 4 menunjukkan bahwa sebagai besar $(83,33 \%)$ memiliki kesan yang baik terhadap kemampuan video SRI menunjukkan proses budidaya dengan metoda SRI secara jelas, audio dan visual yang menarik dan mudah dipahami. Dalam video ini menjelaskan setiap proses budidaya mulai dari persiapan kompos, persiapan mikroorganisme lokal (mol), persiapan pestisida nabati, persiapan lahan dan benih, penanaman dan pemeliharaan tanaman serta panen dan pasca panen.

Sebuah media audio visual (video) menjadi menarik karena sifat media yang dapat melibatkan indra pendengaran maupun penglihata, seperti yang dikemukakan Yudhi Munandi (2008) bahwa media audiovisual adalah media yang melibatkan indera pendengaran dan penglihatan sekaligus dalam satu proses. Sama halnya dengan pendapat yang dikemukakan oleh Wina Sanjaya (2008) menyatakan bahwa media audiovisual adalah jenis media yang selain mengandung unsur suara juga mengandung unsur gambar yang bisa dilihat.

Salah satu hal yang menarik perhatian petani adalah unsur kedekatan petani dengan gambar-gambar atau visualisasi yang ditampilkan dalam video ini, yaitu penggunaan actor dari kalangan petani itu sendiri dan proses pengambil gambar dilakukan lokasi dimana petani berada. Menurut Mardikanto (2007) salah satu prinsip yang harus dipenuhi dalam proses belajar dalam kegiatan penyuluhan pertanian adalah prinsip kesiapan (readiness). Dalam prinsip ini kegiatan belajar akan berhasil jika mampu memahami keadaan peserta didiknya baik keadaan fisik maupun kesiapan sasarannya. Penggunaan actor dikalangan petani dan pengambilan gambar dilokasi setempat mampu menunjukkan bahwa petani mampu dan siap menerapkan metoda SRI ini.

Dengan media video, petani merasa lebih tertarik dan lebih mudah memahami pesan yang disampikan (metoda SRI) karena mereka dapat mendengar penjelasan sekaligus melihat secara langsung teknik atau cara-cara dalam metoda SRI. Menurut Yudhi Munandi (2008) mengemukakan media audiovisual adalah media yang melibatkan indera pendengaran dan penglihatan sekaligus dalam satu proses. Begitu juga dengan Daryanto (2010) menjelaskan bahwa media audio visual adalah media yang dapat didengar dan dilihat sehingga dapat menyampaikan pengertian atau informasi dengan cara yang lebih konkrit daripada yang disampaikan secara lisan atau ditulis.

Beberapa kelebihan dari media video menurut Daryanto (2010:40) yaitu: 1) gambar yang diproyeksikan secara jelas akan menarik perhatian, 2) isi dapat dilihat berulang-ulang serta dapat diputar kembali, sesuai bagian yang diinginkan, 3) pemakaian tidak terikat oleh waktu dan 4) sangat praktis dan menyenangkan.

\section{KESIMPULAN}

Dari hasil penelitian terhadap persepsi petani terhadap video penyuluhan pertanian System of Rice Intensification (SRI) sebagai media informasi pertanian organik bagi petani di Kelompok Tani Bina Lingkungan Kecamatan Andong KAbupaten Boyolali, dapat ditarik kesimpulan sebagai berikut:

Sebanyak $73,33 \%$ petani responden memiliki persepsi yang baik terhadap kemampuan video SRI dalam menarik perhatian petani,

a. Sebanyak $70,00 \%$ responden memiliki persepsi yang baik terhadap kemampuan 
video SRI menunjukkan pentingnya pertanian organik,

b. Sebanyak $73,33 \%$ responden memiliki persepsi yang baik terhadap kemampuan video SRI menunjukkan solusi terhadap masalah petani dan

c. Sebanyak $83,33 \%$ responden memiliki persepsi yang baik terhadap kemampuan video SRI dalam menunjukkan proses yang jelas, audio dan visual yang menarik dan mudah dipahami.

Dengan demikian dapat disimpulkan bahwa petani memiliki persepsi yang baik terhadap video penyuluhan pertanian SRI sebagai media informasi pertanian organik bagi petani karena memenuhi unsur attention, needs, satisfaction dan visualization. Diharapkan media video penyuluhan ini mampu mempercepat proses diseminasi metode SRI di kalangan petani.

Media audio visual (video) merupakan media yang cukup baik untuk membantu proses diseminasi metode SRI bagi petani. Media ini dapat menjangkau sasaran masyarakat petani yang lebih luas dengan memanfaatkaan salah satu aplikasi dalam media baru yaitu youtube. Aplikasi ini telah banyak diakses oleh semua kalangan, dengan demikian proses edukasi melalui media video tidak hanya dikonsumsi oleh masyarakat petani, namun juga mampu mengedukasi masyarakat umum untuk tertarik di bidang pertanian.

\section{DAFTAR PUSTAKA}

Agroindonesia. 2015. Penambahan tenaga penyuluhan.

http://agroindonesia.co.id/index.php/2015

/07/14/penambahan-tenaga-penyuluh.

Diakses 16 September 2016.

Anonim. 2016. Modul media penyuluhan pertanian - STPP Bogor. www.stppbogor.ac.id. Diakses 16 September 2016.

Azhar Arsyad. 2004. Media Pembelajaran. PT. Raja Grafindo Persada. Jakarta

Daryanto. 2010. Media Pembelajaran. Gava Media. Yogyakarta

Departemen Pendidikan Nasional. 2001. Kamus Besar Bahasa Indonesia. Balai Pustaka. Jakarta.
Direktorat Jenderal Prasarana dan Sarana Pertanian. 2014. Laporan Kinerja Ditjen Prasarana Dan Sarana Pertanian TA. 2014. Direktorat Perluasan Dan Pengelolaan Lahan Kementrian Pertanian. Jakarta

Juliandi, Azuar, Irfan dan Saprinal Manurung. 2014. Metodologi Penelitian Bisnis, Konsep dan Aplikasi. UMSU Press. Medan.

Kriyantono, Rachmat. 2006. Teknik Praktis Riset Komunikasi. Kencana Prenada Media Group. Jakarta.

Mardikanto, Totok. 1993. Penyuluhan Pembangunan Pertanian. Sebelas Maret University Press. Surakarta.

Pertanian. $\begin{gathered}\text { 2007. Sistem Penyuluhan } \\ \text { Pusat Pengembangan }\end{gathered}$
Agrobinis dan Perhutanan Sosial
(PUSPA). Sukoharjo

Mars, S. and D. Pannel. 1999. Agricultural extension.- a decade of change.Australia: RIRDC. http://www.rirdc.gov.au/pub/ shortreps/sr66.html

Munandi, Yudhi. 2008. Media Pembelajaran. Cipayung-Ciputat: Gaung Persada.

Purwasasmita Mubiar \& Alik Sutaryat. 2014. Padi SRI Organik Indonesia. Penebar Swadaya. Jakarta Timur

Robbins, Stephen P \& Timothy A. Judge. 2007. Perilaku Organisasi, Edisi 12. Salemba Empat. Jakarta.

Syam, Nina Winangsih dan Dadang Sugiana. 2007. Perencanaan pesan dan media. Universitas Terbuka. Jakarta

Ukrita, I., Feri Musharyadi, \& Silfia. 2011. Analisa prilaku petani dalam penerapan penanaman padi metode SRI (System Rice of Intensification) (Kasus: Kelompok Tani sawah Bandang di Kanagarian Koto Tuo Kecamatan Harau Kabupaten Limapuluh Kota). Jurnal Penelitian Lumbung, Vol. 10, No. 2, Juli 2011

Wina, Sanjaya. 2008. Pembelajaran dalam Implementasi Kurikulum Berbasis Kompetensi. Jakarta : Prenada Media. 